\title{
U.S. Regionalism: Evolution Of An Era
}

\author{
Monroe Newman *
}

It is now more than thirty years since the United States formally committed itself to a policy of seeking maximum employment. Since the passage of the Employment Act in 1946, myriad actions have been taken to try to achieve the goals of economic efficiency and equity that that Act establishes. In numerous ways, that law marked a watershed in national domestic policy by making it an obligation of the Federal government consciously to seek means to those goals. Sub-national economic development policy has been one expression of striving toward the goals established by the Act.

Even after the 1946 Act, there was a lengthy struggle before there was acceptance of a need for a Federal policy toward sub-national areas. The first focus was the so-called "pockets of unemployment" whose distress and persistence achieved national attention in the 1950's. Their problems were addressed twice by legislation passed by Congress only to be vetoed by President Eisenhower. Presidential rejection was philosophically based and turned basically on the responsibilities of the national government in a federal system. The vetoes argued, in essence, that localized unemployment was not a suitable cause for national action. In the background was the contention that a market directed process of equilibration would alleviate the problem and that interference in the process by providing Federal assistance would be costly and unwise. These beliefs stymied attempts to initiate a sub-national economic development program until fifteen years after the passage of the Employment Act.

\section{A New Federal Commitment}

Presidential acceptance of the Area Redevelopment Act in 1961 moved the U.S. into the era of sub-national economic development programming. Though that Act was superseded only four years later, at least two of its characteristics have been fundamental to succeeding programs. The first was the attempt to alter the economic fortunes of the people of an area by attempting to improve the cost/supply conditions of the area. The second, which is implicit in the first, was the focus on indirect transfers as a means to remedy perceived income inequities. No direct payments to alleviate personal distress were provided. Rather, individuals were expected to find their economic circumstances improved as the resources (including human resources) of the area gained more competitive at-

\footnotetext{
* Professor of Economics, The Pennsylvania State University.
} 
tractiveness and drew to the area a share of the growth of the national economy.

It was not expected that area redevelopment policies would beneficially affect the level of national output. Rather, their impact was expected to be on the spatial pattern of activity. Implicitly, it was also expected that upgrading of the labor force through training would lead to in-migration of jobs, not out-migration of the trainees.

The antecedents, operating experience and early demise of the Area Redevelopment Administration (ARA) have been well discussed elsewhere. ${ }^{1}$ What is important here is to note the strategy for redevelopment that was adopted in the 1961 law. Two key elements were 1) the decision to try to affect the supply side of the locational equation and 2) to try to improve the fortunes of those in distress by inducing economic activity in their immediate locale, typically the county of residence.

Disenchantment with ARA led to its replacement, rather than its renewal, when the four year term of the original legislation expired. However, the disenchantment did not extend to a total disavowal of the principal elements of its development strategy. In fact, the first (the emphasis on the cost/supply side) persisted without alteration. There was ambivalence on the second strategy element. Some of the 1965 laws retained the local employment stimulation orientation of the 1961 Act, the other rejected it and with that rejection, also eschewed the prior standards for eligibility for aid.

\section{TInresolved Strategy Choices}

The ambivalence of Congress on this fundamental element of strategy is dramatically evident from an examination of the two area economic development laws passed in 1965. These remain our basic statutes on the subject. The first enactment in 1965 was the Appalachian Regional Development Act (ARDA) which stipulated an investment strategy and criteria for eligibility that were markedly different from those contained in the 1961 law. An entire multistate region was legislatively determined to require development assistance rather than the practice in the 1961 law of reserving eligibility for individual local areas that qualified on the basis of statistical evidence of distress. Within that designated region, priority was to be given to areas with significant potential for future growth. Such areas might not have qualified for assistance under the 1961 law but their development, it was hoped, would produce benefit spillovers to near-by areas with relatively low incomes and high unemployment. Congress broke the previously inflexible link between the local evidence of distress and the location of remedial attempts.

Within a few months of passing the law that created the Appalachian Regional Commission (ARC), Congress passed the Public Works and Economic Development Act of 1965 (PWEDA). In this law, two actions were taken that are relevant here-a revised extension of the 1961 local 
area development program and a grant of permission in Title $\mathrm{V}$ for the creation of regional commissions by the Secretary of Commerce upon application of the states concerned.

This discussion is concerned primarily with the regional aspects of PWEDA. However, some comment on the local area development program changes are relevant. First, the 1965 law permits and encourages the establishment of multi-county economic development districts which may include an adjacent, otherwise ineligible county if it contains an urban center whose growth would benefit the nearby distressed counties. In other words, Congress legislated both the county-by-county investment strategy of the 1961 law and an adaptation of the growth area strategy it had recently incorporated into the ARDA.

Second, there was nothing in the PWEDA to ensure that the strategies of the Title $\mathrm{V}$ commissions and of the Economic Development Administration (the successor to ARA), both administered in the Department, would be coordinated or even compatible.

Clearly, Congress had not made up its mind among the alternative strategies-and still has not-because the situation created in 1965 perrists. An opportunity to choose a preferred strategy, including termination, will arise prior to September 30, 1979 when both ARDA and PWEDA are due to expire. The imminence of the date has been the occasion for these comments on the background and experiences of regional commissions.

\section{$A R C$ and Title V's}

The ARC and the commissions created under Title V of the PWEDA have superficial similarities. All operating commissions are multi-state; they are charged with an economic development function; and they are composed of a Federal Co-chairman and the governors of the states involved. Beyond that, there are profound differences. ARC has a mandated development strategy and a far more substantial appropriation. ARC is also an independent Federal-State entity, so it is not within a Federal line agency. These differences are far more significant than the surface similarities.

One common feature that may affect the evaluation of the commissions is that no state has chosen to leave a regional commission once it joined. Rather, the experience has been that the commissions have tended to enlarge once established. Parts of two states (Mississippi and New York) have been added to the original Appalachian region designated by Congress. $^{2}$ As the following table shows, three of the eight operating Title V Commissions have had similar experiences. The table also emphasizes the relevant point that there has been a tendency for regions that consisted of parts of states to grow to include the entire state.

In addition to the areas in organized commissions, additional regions have been proposed to include the non-Appalachian parts of Alabama, 
Composition of Title V Regional Commissions

\begin{tabular}{|c|c|c|}
\hline Region & Original Boundaries & Additions \\
\hline Coastal Plains & $\begin{array}{l}\text { Parts of Georgia, North Caro- } \\
\text { lina and South Carolina }\end{array}$ & $\begin{array}{l}\text { Rest of non-Appalachian } \\
\text { Georgia and South Caro- } \\
\text { lina plus parts of Vir- } \\
\text { ginia and Florida }\end{array}$ \\
\hline Fcur Corners & $\begin{array}{l}\text { Parts of Arizona, Colorado, } \\
\text { New Mexico and Utah }\end{array}$ & $\begin{array}{l}\text { Rest of member states plus } \\
\text { all of Nevada }\end{array}$ \\
\hline New England & $\begin{array}{l}\text { All of Connecticut, Maine, } \\
\text { Massachusetts, New Hamp- } \\
\text { shire, Rhode Island and } \\
\text { Vermont }\end{array}$ & None \\
\hline Old West & $\begin{array}{l}\text { All of Montana, Nebraska, } \\
\text { North Dakota, South } \\
\text { Dakota, Wyoming }\end{array}$ & None \\
\hline Ozarks & $\begin{array}{l}\text { Parts of Arkansas, Kansas, } \\
\text { Missouri, Oklahoma }\end{array}$ & $\begin{array}{l}\text { Rest of member states plus } \\
\text { all of Louisiana }\end{array}$ \\
\hline Pacific Northwest & $\begin{array}{l}\text { All of Idaho, Oregon and } \\
\text { Washington }\end{array}$ & None \\
\hline Upper Great Lakes & $\begin{array}{l}\text { Parts of Michigan, Minnesota } \\
\text { and Wisconsin }\end{array}$ & None \\
\hline Southwest Border & $\begin{array}{l}\text { Border counties of Arizona, } \\
\text { California, New Mexico } \\
\text { and Texas }\end{array}$ & None \\
\hline
\end{tabular}

Kentucky, Mississippi and Tennessee, all of Illinois, Indiana, Iowa and Ohio, all of Delaware, Maryland, New Jersey and Pennsylvania, and one for the Virgin Islands and Puerto Rico. Moreover, the law allows the establishment of single state regional commissions in Alaska, California, Hawaii and Texas. Were all this to come to pass, every state would have at least part of its area in a regional commission. In addition, some parts of some states would be in more than one region. The rhyme and reason for all this needs examination.

The first question that comes to mind is: How is it possible for so much of the United States to be experiencing sub-par performance and be in need of "public works and economic development"? As already stated, Appalachia's boundaries were determined by Congress and, in fact, at the time the boundaries were established all areas included were below national averages for per capita income and above the norm for unemployment. To be included in a Title V commission, the Secretary of Commerce must consider if, among other (unspecified) factors the areas proposed have some of the following attributes:

1. the rate of unemployment is substantially above the national median;

2. the median level of family income is significantly below the national median; 
3. the level of housing, health, and educational facilities is substantially below the national level;

4. the economy of the area has traditionally been dominated by only one or two industries which are in a state of long-term decline;

5. the area is adversely affected by changing industrial technology;

6 . the area is adversely affected by changes in national defense facilities or production;

7. the rate of out-migration of capital or labor or both is substantial; and

8. indices of regional production indicate a growth rate substantially below the national average.

Given these diverse criteria, it is not surprising that the areas in some Title V commissions record above average per capita incomes (New England and Pacific Northwest are examples) or have as their principal concern the management of growth rather than its stimulation. Examples of the latter are the Old West Commission and, again, the Pacific Northwest.

A second question that comes to mind when faced with the spread of regional commission is: What has been their allure? An obvious answer is the opportunity to receive Federal money. Appalachia has been receiving around $\$ 250$ million a year and that is certainly not an insubstantial amount of money. However, prior to FY $76 \& 77$, the total appropriation to all the Title V Commissions combined was only about $\$ 40$ million annually and in more recent fiscal years was close to $\$ 65$ million. That is fractionally less than $\$ 1$ per inhabitant of the Title $\mathrm{V}$ areas (about 66 million people). It is hard to visualize funding at these levels to be a great attractant.

It may be that the ephemeral prospect of enlarged future appropriations has been the lure but the appropriations record is a frail basis for that belief. It may be also that the adverse consequences to an area of not following the actions of other areas which do join are perceived to be greater than the benefits of independent action. Emulation may be a strong factor. If one is not too jaded, another explanation comes to mind. Perhaps the attraction to join and enlarge regional commissions comes from the fact that they are effective.

\section{Evaluations}

By law, the charge to all regional commissions is to help their areas pursue economic development and this is therefore an obvious criterion of effectiveness. However, a fundamental impediment to employing this standard of judgment must be considered. Our conceptual and statistical abilities do not permit us to discern an effect from even the level of funding provided to ARC, let alone the meager resources of the Title $\mathrm{V}$ commissions. Although logic may tell us that some impast on economic performance should be occurring, if it is, it is lost in the cross-currents of 
changing patterns and levels of national economic activity and in the much larger volume of expenditures by other public programs. Only in rare and isolated cases should we expect to be able to apply cost/benefit or even cost/effectiveness criteria to the present programs, given the level of funding and the limitations of our conceptual understanding.

Despite this fact, the Title V commissions and ARC (which has been much more closely scrutinized than its newer counterparts) have generally received favorable evaluations, despite recognized flaws and failure. $^{3}$ Different evaluators have focused on somewhat different aspects of the overall experience in making their judgments.

In the case of ARC, one obviously favorable effect of the dozen years of experience has been the creation of a considerably altered infrastructure, a substantial portion of which produces what would generally be designated as merit goods. Facilities for the provision of a wide range of health and education services, innovation in their provision, and creation of institutional capability and experience in such disparate fields as housing and mine area restoration all suggest that the region has received a favorable impact from ARC's activities.

More commonly examined and evaluated has been the process by which ARC decisions are made. The attempt to follow a strategy and the priorities it implies have been applauded, as has been the allocation of resources in conformance to them.

Considerable attention has been devoted to ARC's planning process and to the linkage between the evaluation of problems and potentials in state plans and the projects actually undertaken. It has been judged that, although further improvements in this linkage would be useful, a better than fair record has been achieved.

From an institutional standpoint, favorable comment has been made about ARC's blending of local, state and national perspectives in policy and program decisions. A major claim for the regional approach is the ability of the commission format to adapt national programs to regional needs while retaining a sense of national priorities. Those who find merit in the ARC performance tend to place considerable emphasis on this attribute. They see in the ARC model a better way to conduct and administer the public's business, well beyond the confines of conventionally defined "economic development" although that is an important part of the range of possible activities.

Essentially what is visualized is an expanded impact from the commission's plans and priorities for the region and its competent areas-an impact on a wide range of local, state and national domestic programs. Unfortunately, in this respect, the recorci does not disclose a high rate of achievement in Appalachia. Explanations for this gap between anticipation and realization have focused princinally on:

1. the relative newness of the entire concept of coordinating public actions by this means and the lack of a legislative mandate in the laws of many relevant programs; 
2. the extent to which improvements are needed in planning at state and local levels;

3. the hostility to the regional commission concept during the Nixon years (particularly around 1972 and 1973) which impeded attempts to influence Federal programs; and

4. a budget level that is insufficient to command the attention of other agencies and, through joint funding, to influence the allocation of their resources.

If ARC's funding level has been insufficient to achieve this general, public administrative goal, the same clearly applies to the Title V commissions. In addition, any efforts they might have made in this direction had the additional impediment of their location within the Department of Commerce. They would have had to rely upon the ability of the Sec. retary of that Department to coordinate the activities of his or her equals-something that the law did not effectively require and that was not achieved even with EDA which is within Commerce.

The Title V commissions were required to prepare multi-year development plans for their regions. After an assessment of the situation and the specification of a program, these plans set spending targets which totalled in the billions-sums that were extravagantly greater than any resources likely to be available. Having satisfied this requirement, the Title V commissions proceeded to show remarkable adaptability and found a wide range of behavioral modes to use the lesser resources available. Some reserve their funds for general projects (such as tourism development) that may impact the entire area or a large part of it. Some allocate their resources among member states and exercise little restraint on their use. One develops comparative ratings of projects that come from the states and consequently stimulates interstate competition for funds. Combinations of these allocative strategies exist and some have markedly altered their use of funds over time.

Staffs tend to be small in comparison with that of ARC; the use of staffs vary. In some Title $\mathrm{V}$ regions the staffs basically augment state capabilities. In others, the staffs serve as a multi-state resource pool helping to create both a cadre of expertise available to all and a sense of regional identity.

This latter is noteworthy. The opportunity for the governors to meet, discuss regional conditions, and utilize modest funds and Federal support to lessen adverse conditions, has been an attraction that helps explain, in part, the spread and persistence of Title $\mathrm{V}$ commissions. They have apparently responded to a perceived need for a recognition of regional commonality within the Federal system.

\section{The Future}

If it can be anticipated that regional commissions can have a beneficial impact on the way we implement programs, if they can provide a mech- 
anism for reconciling national and sub-national priorities, then the era that began in 1961 may not end on September 30, 1979. Should that be the case, a number of difficult issues will need to be decided. Seeking answers to these and other questions may not be an idle exercise, as confirmed by the following recent statements.

Speaking at the Appalachian Conference on Balanced Growth on October 28, 1977, Vice President Mondale said "I would suspect today that there are no programs on the books that would be harder to repeal, because of its [sic] uniform support, than the Appalachian region legislation.".4

A little more than a month later Senator Jennings Randolph, who chairs the Senate Committee on Environment and Public Works, told a meeting of ARC "... I am gratified at a recommendation ... for a national system of regional commission. It is timely ..."

It is timely therefore to raise some fundamental questions of policy that will require resolution in national legislation. The first, and one of the knottiest, is the relationship between the commissions and our major urban areas. Though widely recognized as a paramount domestic issue, urban problems have not been the focus of either the existing regional commissions or of EDA. A combination of factors, involving the geography of the operating regional agencies, levels of funding, political pressures, and divided responsibilities in the Federal government have made major urban areas the "turf" of the Department of Housing and Urban Development, rather than the economic development agencies. That could not continue in a nationwide regional program. It will be necessary to determine the procedure for representing the urban point of view in regional commission decision processes, to determine an appropriate division of responsibility between HUD and the commissions, and to establish suitable funding levels. To gain at least tacit support from "big city" mayors, some means that is internal to the commission will have to be found to assure the mayors that their problems are high on commission agendas. This is particularly true if some of what the Administration sees as scarce "new money" for social programs is allotted through regional commissions.

The funding decision is intimately connected to another fundamental issue, namely the range of activities in which commissions are permitted to engage. Should they, for example, be restricted to supplementing the funding levels of existing Federal programs (their accustomed role) or should they be allowed to enlarge the scope of Federal development aids with entirely new programs? No matter which of these options is chosen, what constraints in addition to the obvious fiscal one, should be imposed?

Not only would the character of regional programs be determined by the answers to these questions, but the answers to other questions are implied. For example, restricting the commissions to the supplementation of existing programs makes it unnecessary for them to develop the staff capability to administer programs. Rather they could contract to give 
their aid through the agencies that normally administer the program to be augmented, thus saving overhead and avoiding duplicating personnel. This clearly requires that the regional programs be built out of existing Federal tools, a possibly severely limiting constraint on a region's response to its problems or opportunities.

Two virtues of such a limitation should not go unnoticed, however. One is that it would limic regional program components to tools that Congress has explicitly sanctioned. Secondly, it would limit the threat felt by the existing agencies from this new competition for "their" clientele since no duplication of operating personnel would be involved.

This is not a trivial concern. The effectiveness of the regional approach would depend to a significant extent on the ability to induce existing agencies to use funds appropriated to them in ways that are compatible with the plans and strategies of each commission. This can be gained, in part, by working with the existing programs in the process of augmenting their funds. But it also takes good will, a resource that is easily squandered. Kind, cooperative feelings toward a new competitor are a rare reaction.

This fact, plus the experience of the existing commissions, leads to another set of significant issues. The Federal representative on each of these commissions would have to have both independence and stature in the Federal establishment. If they are submerged in an existing department, they are unlikely to wield much influence in it, let alone in dealings with other departments. Being charged to coordinate among one's equals or superiors is to be charged with the impossible. Independence from cabinet departments seems essential. And stature in the executive arm is inversely related to administrative distance from the Office of the President. The potentials for success of regional commissions might be determined by the decision about that distance.

Another troublesome area requiring resolution concerns the geographic configuration of these regions. How many should there be? What states should be joined? Must they be composed of whole states? How will these alliances be formed? Beyond these issues is the process for allocating funds to these regional agencies. How will the competition among them be muted and productively channeled?

These are all troublesome questions and one may ask if it is worth the effort to try to resolve them. If the extent of discontent with the administration and effectiveness of domestic programs is any indication, the answer is a resounding "yes."

\section{FOOTNOTES}

1Sar A. Levitan, Federal Aid to Depressed Areas, Johns Hopkins Press, 1964.

2Present members are parts of: Alabama, Georgia, Kentucky, Maryland, Mississippi, New York, North Carolina, Ohio, Pennsylvania, South Carolina, Tennessee, Virginia and all of West Virginia.
3 Probably the most negative, extended examination was that by Martha Derthick, $\mathrm{Be}$ tween State \& Nation, Brookings Institution, 1974 who questioned the need for and efficacy of a wide range of multi-state agencies, including regional commissions. Others who came to more affirmative evaluations include Richard 
E. Schmidt, Regional Development Commissions: An Alternative Federal Intervention Strategy, Working Paper 2-0090-10-2, The Urban Institute, 1977; the Advisory Commission on Intergovernmental Relations, Multi-State Regionalism, 1972; Donald Rothblatt, Regional Planning: The Appalachian Experience, Lexington Books, 1971; Niles Hansen, A Review of the Appalachian Regional Commission Program, University of Texas, 1969; Monroe New- man, Political Economy of Appalachia, Lexington Books, 1972; and Richard Pascale \& G. P. Barbour, Jr., Shared Power, America Enterprise Institute for Public Policy Research, 1977. For a review of the Title V commissions, see A. D. Little Inc., Regional-Action Planning Commission-An Evaluation, 1970. 11.

Appalachia, November-December 1977, p. PPress release, December 8, 1977, p. 2. 